\title{
Loss and damage research for the global stocktake
}

To the Editor - The Paris Agreement includes the concept of a global stocktake (GST), a process by which progress on climate action is assessed ${ }^{1}$. The first GST in 2023 will provide a critical opportunity to review overall progress made on mitigation, adaptation and means of implementation and support. Due in part to strong advocacy by small island developing states (SIDS) and least developed countries (LDCs), additional thematic areas - including efforts related to averting, minimizing and addressing loss and damage (L\&D) - will be part of the process $^{2}$. However, despite the increase in literature focused on L\&D since 2010 (refs. ${ }^{3,4}$ ) and its recent inclusion in IPCC reports and processes $^{5}$, there remain significant research gaps on $\mathrm{L} \& \mathrm{D}$ that need to be addressed to support a robust GST.

First, most L\&D research has been theoretical, focused on conceptualizations of L\&D from a variety of perspectives and linkages to other policy frameworks, with significantly less empirical research ${ }^{4}$. While advancing conceptualization of L\&D is important, the GST focuses on Paris Agreement implementation and opportunities for enhanced action and support. The United Nations Framework Convention on Climate Change (UNFCCC) itself has largely focused on improving knowledge and strengthening dialogue about L\&D, with considerably less advancements on increasing action to enable developing countries to address $\mathrm{L} \& \mathrm{D}^{6,7}$. Thus, there is a critical need for more empirical information to aid in identification of where and what type of action and support is needed, what works and in which contexts, and how such action and support can be delivered. Research can be provided from both the natural and social sciences along the entire L\&D spectrum ${ }^{8}$, ranging from potential risks and preventive risk reduction strategies to observed impacts and reactive actions taken.

Second, $\mathrm{L} \& \mathrm{D}$ research is not presented in a way that is clearly linked to the UNFCCC framing of L\&D. For example, less than $20 \%$ of L\&D publications utilize a framing of or refer to comprehensive risk management, which is currently used within the UNFCCC to categorize L\&D activities ${ }^{4}$. Simply using wording that indicates the research relates to risk assessment, reduction, transfer, retention or recovery may increase the likelihood that it will be used to inform the GST. Additionally, there is research relevant to L\&D but does not use the particular term 'loss and damage'. Research on impacts, risks, residual risks and limits to adaptation are closely linked to L\&D. Explicitly using these terms in abstracts or directly relating results to $\mathrm{L} \& \mathrm{D}$ is another simple but potentially effective way of enhancing relevance for the GST. Further, categorization of research according to whether insights relate to slow onset or extreme events, and whether economic and non-economic losses are described, would make it more likely that they are recognized as relevant. The framing of transformative adaptation also has potential implications for how L\&D is defined and accounted for, and therefore the overlap between these two concepts is worthy of further investigation.

Third, the majority of research on L\&D has originated from the developed world, with over $70 \%$ of L\&D studies coming from institutions in Europe and North America $^{4}$. More research originating from the developing world is needed, as this plays a role in epistemologies and framings of L\&D. SIDS and LDCs have been strong proponents of including L\&D as part of the UNFCCC and it is critical that the experiences and perspectives of these groups are well represented in the $\mathrm{GST}^{9}$. More systematic research into how SIDS and LDCs in particular are coping or failing to cope with L\&D is essential, including an increased effort in attributing observed impacts to anthropogenic climate change $\mathrm{e}^{10,11}$. This might include consideration of how L\&D terminology reflects, and is applied to, the contextual realities of LDCs and SIDS. For example, as adaptation options increasingly involve trade-offs, limits to adaptation may be experienced quite differently by different stakeholders, suggesting a more nuanced application of terminology may be required $^{12,13}$. Further and deeper integration of non-economic losses would also be beneficial, particularly in situations where limits to adaptation are forcing consideration of more radical responses.

The GST will be conducted on a five-yearly basis. Absent rapid, substantial and sustained emission reductions will mean that climatic risks will continue to rise with an increasing share of unavoidable L\&D, particularly in developing countries. This means that on the current emissions trajectory there will be more and more to report on L\&D. Research that is empirical, linked to UNFCCC framings of L\&D and responds to the need for more research from SIDS and LDCs will contribute to a robust GST that reflects progress made towards achieving the goals of the Paris Agreement.

\section{Adelle Thomas (D) 1,2ष, Olivia Serdeczny (D)2 and Patrick Pringle (iD) ${ }^{2}$}

${ }^{1}$ Climate Change Adaptation and Resilience Research Centre, University of The Bahamas, Nassau, Bahamas. ${ }^{2}$ Climate Analytics, Berlin, Germany.

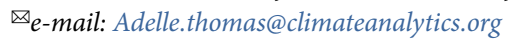

Published online: 1 June 2020

https://doi.org/10.1038/s41558-020-0807-z

References

1. Adoption of the Paris Agreement FCCC/CP/2015/L.9/Rev.1 (UNFCCC, 2015).

2. Report of the Conference of the Parties serving as the meeting of the Parties to the Paris Agreement on the third part of its first session, held in Katowice from 2 to 15 December 2018 FCCC/PA/ CMA/2018/3/Add.2 (UNFCCC, 2019).

3. Mechler, R., Bower, L., Linnerooth-Bayer, J., Schinko, T. \& Surmiski, S (eds). Loss and Damage from Climate Change: Concepts, Principles and Policy Options (Springer, 2019).

4. McNamara, K. E. \& Jackson, G. Wiley Interdiscip. Rev. Clim. Change 10, e564 (2019)

5. IPCC: Summary for Policymakers. In Global Warming of $1.5^{\circ} \mathrm{C}$ (eds Allen, M. et al.) (WMO, 2018).

6. AOSIS Submission on the 2013-2015 Review of the WIM (AOSIS, 2019).

7. LDC Climate Change. Submission by Bhutan on behalf of the Least Developed Countries Group on possible elements to be included in the terms of reference for the review of the Warsaw International Mechanism (WIM) (UNFCCC, 2019).

8. Boyd, E., James, R. A., Jones, R. G., Young, H. R. \& Otto, F. E. L. Nat. Clim. Change 7, 723-729 (2017).

9. van der Geest, K. \& Warner, K. What the IPCC 5th Assessment Report has to say about loss and damage. Report No. 21 (UNU-EHS, 2015).

10. Hansen, G. \& Cramer, W. Nat. Clim. Change 5, 182-185 (2015).

11. Huggel, C., Wallimann-Helmer, I., Stone, D. \& Cramer, W. Nat. Clim. Change 6, 901-908 (2016).

12. Klein, R. J. T. et al. in Climate Change 2014: Impacts, Adaptation and Vulnerability (eds Field, C. B. et al.) 899-944 (Cambridge Univ. Press, 2014).

13. Roberts, E. \& Pelling, M. Clim. Dev. 10, 4-17 (2018). 